\section{Cataract - a global perspective: output, outcome and outlay}

a visual acuity less than $6 / 60$ and this is likely to double in the next 20 years if service delivery does not change (Fig. 2).

Limburg and Kumar ${ }^{3}$ working in Karnataka State in India examined 21950 people over the age of 50 years. The prevalence of cataract causing an acuity of less than 6/60 in either eye was $14.25 \%$. When applied to the total population this gives a figure of 18800 eyes per million population with cataract causing less than $6 / 60$ acuity. In the same study the prevalence of aphakia was $5.26 \%$, giving 6700 aphakic eyes per million population. In 1997, 155256 cataract operations were performed in Karnataka State for a total population of 41.97 million, giving a cataract surgical rate of 3700 cataract operations per million population per year. The incidence of eyes acquiring a visual acuity of less than $6 / 60$ due to cataract each year is unknown, but is estimated at 3000-4000. These data for a population of 1 million people are presented diagrammatically as a model in Fig. 3.

In order to reduce the backlog of eyes having operable cataract it is necessary to develop a service whereby the cataract surgical rate exceeds the incidence. If this rate can be maintained the backlog of eyes having less than 6/60 acuity will decrease. The indication for surgery will then change, and patients having $<6 / 18$ acuity due to cataract will begin to be routinely offered surgery. The incidence and prevalence of eyes with a visual acuity of less than $6 / 18$ due to cataract is obviously greater than for eyes with an acuity of less than $6 / 60$. Therefore in order to deal with eyes with an acuity of less than $6 / 18$ the cataract surgical rate will have to increase, probably to levels in excess of 5000 per million total population per year. This is the cataract surgical rate found in North America and Germany, and in most western industrialised countries the rates are in excess of 3000 operations per million total population per year. However, in middleincome countries of Latin America and parts of Asia the rate is between 500 and 2000, and in most of Africa, China and the poorer countries of Asia the rate is often less than 500 (Fig. 4). One of the reasons for low cataract surgical rates, particularly in Africa, is the lack of eye specialists, which is demonstrated in Fig. 5.
Allen Foster, FRCS, FRCOphth

London School of Tropical Medicine and Hygiene Keppel Street London WC1E 7HT, UK e-mail: allenfoster@compuserve 


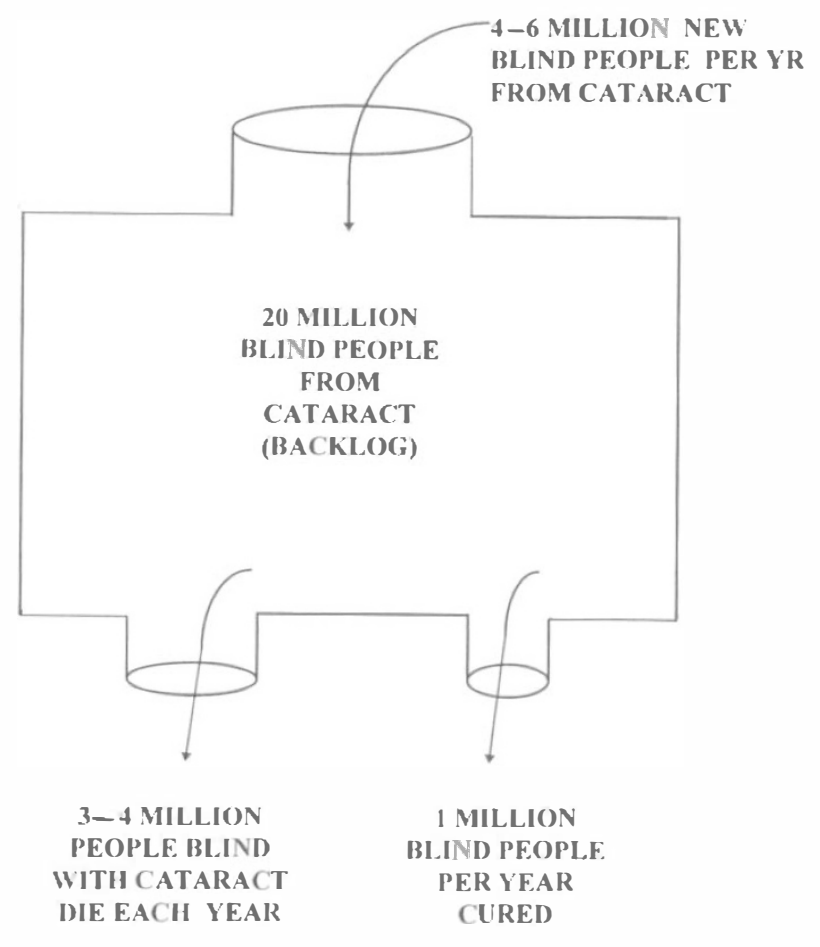

INCREASE - 1 MILLION CATARACT BLIND PEOPLE PER YEAR

Fig. 1. Global estimates for cataract blindness (<3/60 both eyes), 1998.

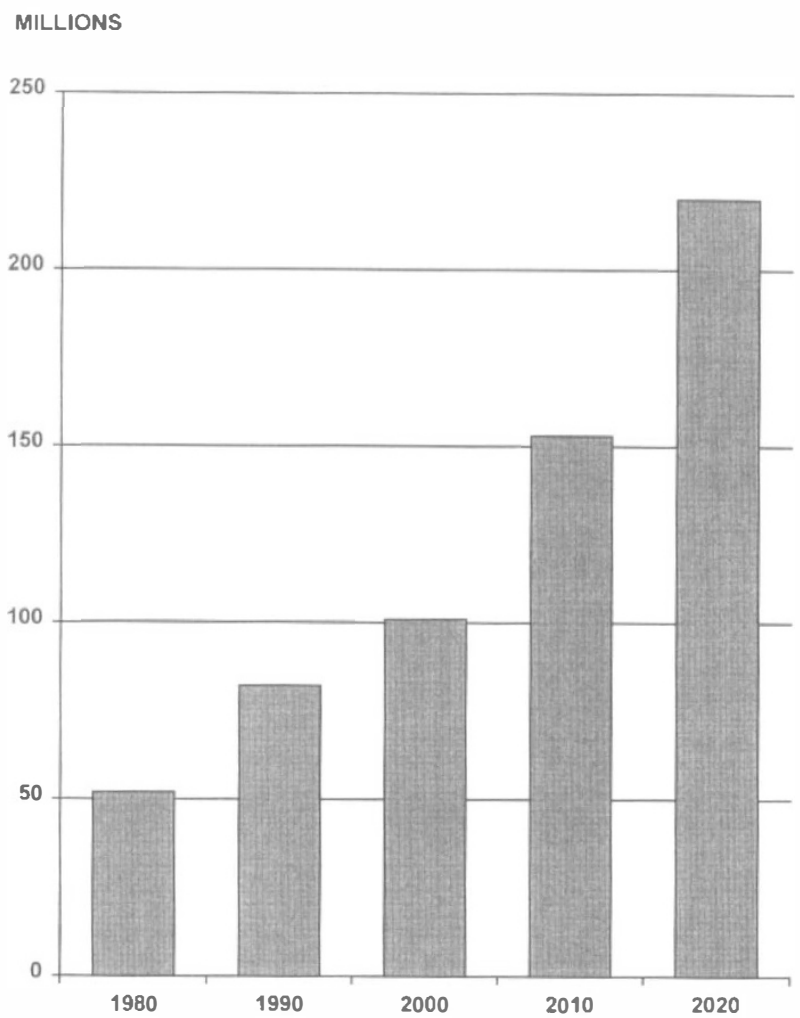

Fig. 2. Global estimates for the number of eyes with visual acuity $<6 / 60$ due to cataract, 1980-2020.
? INCIDFNCE

(Wepends on definition of "operable calaract" maybe $3010-10010$ eyes $<6 / 60$ per year)

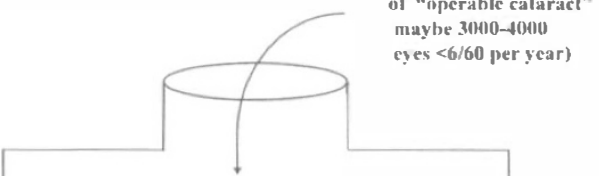

Fig. 3. Situational analysis for cataract services per million population: Karnataka State, India, 1995-1997.

\section{Outcome. What are satisfactory results?}

In order to quantify good or poor outcome following cataract surgery it is necessary to define outcome. Patient satisfaction and quality of life measurements have been used in research studies to document outcome; however, they are time-consuming and not readily available to the routine cataract surgeon. An indicator is required that allows the ophthalmologist to measure performance so as to monitor the quality of service. A recent consultation held by the World Health Organization Prevention of Blindness Programme defined outcome following cataract surgery in terms of visual acuity, which can be assessed with full spectacle correction ('best vision') or with available correction ('functioning vision'). Good

USA

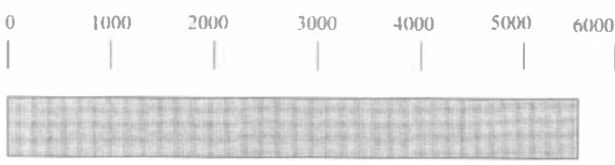

GERMANY

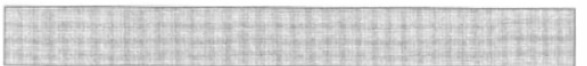

I'K

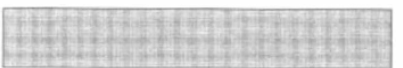

INDIA

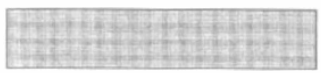

I.ATIN

AMERICA

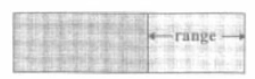

CHINA

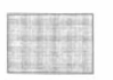

AFRICA

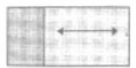

Fig. 4. Estimates of cataract surgical rates (cataract operations per million population per year), 1997. 


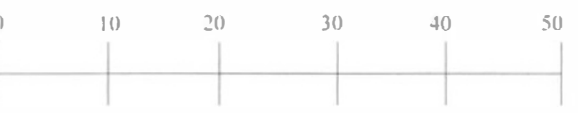

AMERICAS

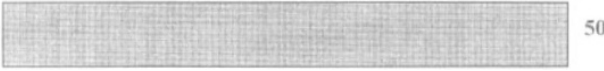

EIROPE

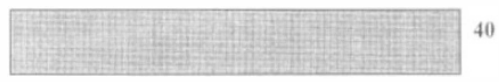

INI)IA

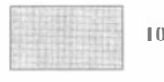

CHINA

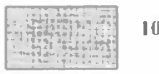

AFRICA

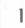

Fig. 5. Number of eye doctors per million population, 1997.

outcome is defined as $6 / 6-6 / 18$, borderline outcome as $<6 / 18-6 / 60$ and poor outcome as $<6 / 60{ }^{4}$ These broad categories can be further subdivided: $6 / 6$ excellent, $6 / 9$ very good, $6 / 12$ good, etc. The time since surgery and conditions under which acuity is measured will obviously affect the results, and these should therefore be standardised for an individual situation so that trends over time can be reviewed. The aim is self-audit over time, not comparison between surgeons or institutions.

Studies from developing countries into the outcome of cataract surgery can be divided into hospital-based studies looking at the results from one or several identified ophthalmologists, and population-based studies which look at the outcome in aphakic eyes in a given community. Several studies conducted in India ${ }^{5}$ and Nepal ${ }^{6-8}$ have documented poor outcome $(<6 / 60)$ with available spectacles (often +10 dioptre spectacles) or with anterior chamber intraocular lenses (IOLs) or posterior chamber IOLs of $0.6-12.2 \%$, and with best correction of $0.4-2.6 \%$. The same studies indicated a good outcome $(6 / 6-6 / 18)$, with available correction in the range $45-80 \%$, and with best correction $90-98 \%$ (Table 1 ).
These studies demonstrate what can be achieved by experienced surgeons working in high-volume centres. Population-based studies, however, have demonstrated much poorer results, with rates of less than $6 / 60$ acuity in the operated eye of $24-53 \%, 4,7,9$ as documented in Table 2.

The causes of poor outcome can be classified as (a) those due to pre-existing eye disease; (b) those due to surgical or post-operative complications; and (c) those due to refractive error. A clinical trial of intracapsular cataract extraction with or without anterior chamber IOL in Nepal showed similar results for both groups. At 1-year follow-up, $5 \%$ of eyes had a visual acuity less than $6 / 60$ with available correction, with half being due to refractive error, and the remainder due to surgical problems and pre-existing eye disease. ${ }^{8}$ A populationbased study by Patil et al. ${ }^{9}$ in Maharashta State, India, reported $31.6 \%$ of 202 aphakic eyes as having $<6 / 60$ functioning vision, of which $58 \%$ was due to refractive error and $34 \%$ due to surgical and post-operative complications. The poor acuity experienced by individual patients following surgery will affect the demand and uptake of cataract services by the community.

\section{Outlay. How can cataract surgery be made affordable?}

The cost of a cataract procedure is made up of various components including the cost of consumables (suture, medicines, IOL or spectacles, etc.), salary costs, overheads (water, electricity, rent, building maintenance, etc.) and a proportion of the cost of the infrastructure, instruments and equipment. There are also significant costs incurred by the patient and family for transport, food and time lost from work.

In order to make cataract surgery affordable the first approach is to minimise the cost of the procedure. Bulk purchase of good-quality but inexpensive sutures, IOLs and medicines can reduce the cost of the consumables in developing countries to levels of $£ 10-20$. The salary and overhead components can be reduced through increased

Table 1. Visual acuity by percentage in the operated eye following cataract surgery at 1-year follow-up, in hospital-based studies in India and Nepal

\begin{tabular}{|c|c|c|c|c|c|c|}
\hline \multirow[b]{2}{*}{ Visual acuity } & \multicolumn{2}{|c|}{ Madurai, India $^{5}$} & \multicolumn{4}{|c|}{ Lahan, Nepal $^{6,8}$} \\
\hline & $\begin{array}{c}\text { ICCE }+ \\
\text { specs } \\
(n=1401)\end{array}$ & $\begin{array}{c}\text { ECCE }+ \\
\text { PCIOL } \\
(n=1469)\end{array}$ & $\begin{array}{c}\text { ICCE }+ \\
\text { ACIOL } \\
\left(n=311,312^{\mathrm{a}}\right) \\
\end{array}$ & $\begin{array}{c}\text { ECCE }+ \\
\text { PCIOL } \\
\left(n=311,312^{\mathrm{a}}\right)\end{array}$ & $\begin{array}{c}\text { ICCE }+ \\
\text { specs } \\
(n=259)\end{array}$ & $\begin{array}{c}\text { ECCE + } \\
\text { specs } \\
(n=259) \\
\end{array}$ \\
\hline \multicolumn{7}{|c|}{ Functioning acuity } \\
\hline $6 / 6-6 / 18$ & 84.9 & 83.9 & 44.7 & 54.3 & 59.8 & 58.3 \\
\hline$<6 / 18-6 / 60$ & 2.9 & 15.4 & 49.8 & 42.4 & 36.7 & 39.4 \\
\hline$<6 / 60$ & 12.2 & 0.6 & 5.5 & 3.2 & 3.5 & 2.3 \\
\hline \multicolumn{7}{|l|}{ Best acuity } \\
\hline $6 / 6-6 / 18$ & 95.5 & 98.1 & 90.4 & 93.3 & 93.0 & 91.5 \\
\hline$<6 / 18-6 / 60$ & 2.9 & 1.3 & 7.1 & 4.8 & 6.6 & 7.3 \\
\hline$<6 / 60$ & 1.6 & 0.6 & 2.6 & 1.9 & 0.4 & 1.2 \\
\hline
\end{tabular}

ICCE, intracapsular cataract extraction; ECCE, extracapsular cataract extraction; specs, spectacles; PCIOL, posterior chamber intraocular lens; ACIOL, anterior chamber intraocular lens.

${ }^{\mathrm{a}} n=311$ for functioning acuity; $n=312$ for best acuity. 


\begin{tabular}{lcccc} 
& & & \multicolumn{2}{c}{ \% eyes with visual acuity less than 6/60 } \\
\cline { 3 - 5 } Place & Year & No. of eyes & With available correction & With best correction \\
\hline Nepal $^{4}$ & 1994 & 159 & 31 & 11 \\
Doumen, China $^{4}$ & 1995 & 109 & 43 & 40 \\
Shunyi, China $^{4}$ & 1995 & 86 & 26 & 40 \\
Karnataka, India $^{7}$ & 1997 & 2401 & 24 & - \\
Ahmedabad, India $^{7}$ & 1992 & 776 & 31 & 13 \\
Nagpur, India $^{9}$ & 1998 & 202 & & \\
\hline
\end{tabular}

productivity. If a surgical team performs five cataract operations on one day but ten cataract operations on another, then the relative cost per case for the salaries and overheads on the second day will be half that of the first day. Therefore, through the purchase of appropriate low-cost consumables and increased productivity it is possible in developing countries to keep the cost of cataract surgery at a level between $£ 20$ and $£ 50$.

However, this cost is still too high for many underprivileged patients in Africa and Asia and therefore some form of subsidy will be required. In Asia one proven method is to provide paying patients with air-conditioned private rooms in order to generate income and so subsidise the cost of cataract surgery for patients on the general wards. Similarly, other eye services such as the sale of reading spectacles or eye medicines can be used to generate income to subsidise poor cataract patients. If cost recovery cannot be implemented internally then the hospital has to look for external sources of subsidy, either from the government, non-government organisations or other service institutions. In principle the aim is to make programmes self-reliant for the running costs of a cataract surgical service, while using external support for development costs such as training and new equipment.

\section{Conclusion}

The number of people blind from cataract in the world is increasing by approximately 1 million per year and similarly the number of operable cataract eyes with a visual acuity of less than $6 / 60$ is increasing by $4-5$ million per year. In order to address this problem eye programmes have to emphasise the delivery of highvolume, good-quality, affordable cataract surgery. The aim is to reduce the amount of time any individual in society spends with blindness or visual loss due to cataract, or as a result of cataract surgery.

Approximately 9 million cataract operations are performed at present each year in the world, giving an overall cataract surgical rate of approximately 1500 per million population per year. In India the rate is nearly 3000 , but in most developing countries of Asia the current cataract surgical rate is between 500 and 1500, and in most countries of Africa it is between 100 and 1000. In order to reduce the cataract backlog it is necessary to have a cataract surgical rate at least as great as the incidence of 'operable' cataract, where 'operable' depends upon the indication for surgery as judged by the patient and surgeon. In Asia, in order to deal with cataract causing an acuity of less than $6 / 60$ it is necessary to do at least 3000 operations per million population per year and perhaps more. In Africa and other parts of the world where there is a lower percentage of elderly people in the population, a realistic target for the next 5-10 years is probably 2000 operations per million population per year.

The 'functioning visual acuity' with available correction is probably the simplest indicator that can be used to monitor the quality of service over time. The aim should be a good outcome with available correction in at least $80 \%$ (and preferably $90 \%$ ) of eyes, and a poor outcome in less than $5 \%$ of eyes. ${ }^{4}$ The causes of poor outcome are pre-existing eye disease, surgical complications and post-operative refractive errors. These can be reduced through avoiding surgery on hopelessly blind eyes, good training and careful surgical technique, and attention to the best available correction for refractive error. The introduction of cataract surgery with IOL implantation should reduce the number of eyes with poor visual outcome due to lost or broken aphakic spectacles. However, good training in IOL surgery is essential to minimise the number of eyes with poor outcome due to surgical and post-operative complications, and further work is required to investigate the role and cost of biometry in developing countries.

The cost of cataract surgery can be kept at a reasonable level through high productivity and cost containment measures including the bulk purchase of low-cost consumables. However, subsidy for poor patients will be required in some situations and various models of cost recovery are in existence in developing countries, including income generation from private patients, and sale of spectacles and eye medicines.

Finally a study has calculated that the economic loss from blindness in 1997 was $\$ 4.4$ million for every million population in India, with cataract being responsible for approximately half of this. The cost of performing 4000 extracapsular cataract extractions with posterior chamber IOLs per year for the same million population would be approximately $\$ 200000$, or $10 \%$ of the economic loss from cataract per year. ${ }^{10}$ Cataract surgery can be a very cost-effective health intervention. 


\section{References}

1. The world health report. Life in the 21st century: a vision for all. Geneva: World Health Organization, 1998:47.

2. Minassian DC, Mehra V. 3.8 Million blinded by cataract each year. Br J Ophthalmol 1990;74:341-3.

3. Limburg H, Kumar R. Follow up study of blindness attributed to cataract in Karnataka state of India: results of district level assessment. Ophthalmic Epidemiol 1998;5:211-23.

4. Informal consultation on analysis of blindness prevention outcomes. Geneva: World Health Organization. WHO/PBL/ 98.68 .

5. Natchiar GN, Thulsiraj RD, Negrel AD, Bangdiwalas S, Rahmatullah R, et al. The Madurai Intraocular Lens Study. I and II. A randomised clinical trial comparing complications and visual outcomes of intracapsular cataract extraction and extracapsular cataract extraction with posterior chamber intraocular lens. Am J Ophthalmol 1998;125:1-25.
6. Hennig A, Pradhan D, Foster A, Johnson GJ, Evans J. One year follow up results of cataract extraction with ACIOLs and PICOLs in Nepal. In preparation.

7. Limburg H, Foster A, Vaidyanathan K, Murthy GVS.

Monitoring visual outcome of cataract surgery: results from India. Bull $\mathrm{WHO}$, in press.

8. Hennig A, Evan JR, Pradhan D, Johnson GJ, Pokherel RP, Gregson RMC, et al. Randomised controlled trial of anterior chamber intraocular lenses. Lancet 1997;349:1129-33.

9. Patil ND, Nangia V, Foster A, Johnson GJ. Community based evaluation of cataract surgical services. Indian J Ophthalmol, submitted for publication.

10. Shamanna BR, Dandona L, Rao GN. Economic burden of blindness in India. Indian J Ophthalmol 1998;46:169-72. 